\title{
Pre- and perinatal characteristics and breast milk immune markers
}

\author{
Jessica Burch ${ }^{1}$, Wilfried Karmaus ${ }^{1,2}$, Venu Gangur ${ }^{3}$, Nelís Soto-Ramírez ${ }^{1,2}$, Mitra Yousefi' and Laura M. Goetzl ${ }^{4}$
}

BACKGROUND: Maternal allergy and gestational exposures can alter the concentration of type-1/type-2/T-regulatory markers in breast milk. We tested whether maternal risk factors are related to breast milk immune markers.

METHODS: Expecting mothers were enrolled in 2008-2010 in South Carolina in prenatal clinics and classes. Interferon (IFN)- $y$-induced protein 10 (CXCL10), CCL11, interleukin (IL)-1 $\beta$, IL-4, IL-5, IL-6, CXCL8, IL-10, IL-12(p70), IL-13, transforming growth factor (TGF)- $\beta 1$, and immunoglobulin (Ig)A in 115 whey samples were measured by immunoassays. Maternal asthma, eczema, rhinitis, smoking, urogenital infections during gestation, pet exposure, education, race/ethnicity, age, body mass, and the child's birth date and sex were ascertained. The effects of these risk factors on immune markers were estimated using general linear models.

RESULTS: Maternal asthma was linked to higher levels of IL-5, rhinitis to lower levels of IL-5 and INF- $\gamma$, and eczema to lower levels of IL-6. Gestational smoking was related to increased concentrations of CXCL8 and IL-6. African-American mothers had markedly higher levels of IL-6, IFN- $\gamma$, and CXCL8. Urogenital infections, maternal age, body mass, child's sex, and season of birth contributed to the variation.

CONCLUSION: The impact of maternal allergies on immune markers in breast milk was small compared with that of maternal nondisease characteristics.

$\mathbf{T}$ he prevalence of allergic diseases, including asthma, eczema, and rhinitis, has increased significantly in past decades. Studies have reported that breastfeeding may influence the development of atopic disease (1-3). Breast milk contains a large number of immune-modulating factors (e.g., cytokines, chemokines, immunoglobulins (Ig), enzymes, and hormones) that are thought not only to allow the development of the infant's immune system but also to protect the infant from infection and gut inflammation $(2,4,5)$. Because cytokines and chemokines are significant immune-modulating agents found in breast milk, identification of factors that influence their levels in breast milk is of importance. Knowledge on breast milk immune markers will help to evaluate future disease risks of breastfed infants.
Several studies have reported different concentrations of immune constituents in breast milk obtained from atopic vs. nonatopic mothers $(2,4,6,7)$, in addition to that obtained from mothers whose children developed cow's milk allergies compared with mothers having nonallergic children $(3,5)$. Hence, exposures to different levels of immune factors through breast milk are considered to affect the occurrence of childhood allergies. However, relatively few studies have examined factors (e.g., maternal allergy) that may alter breast milk cytokine/ chemokine and IgA levels $(2,4,5,8,9)$. Circumstantial evidence suggests that maternal allergy may be an important factor because a history of maternal asthma, rhinitis, and eczema seems to increase the risk of allergic diseases in infants (10). Studies have reported that mothers with allergic disease have a lower concentration of T-regulatory cytokine and transforming growth factor (TGF)- $\beta 2$, but elevated interleukin (IL)-10 level, in addition to having higher levels of type-2 cytokines (IL-4, IL-5, and IL-13) than healthy mothers $(4,5)$. However, allergic diseases in infants may also be related to other maternal factors, such as maternal smoking, pet ownership, race/ ethnicity, and education, which in turn could affect breast milk cytokines, chemokines, and IgA levels (11). Although most of these factors have not been investigated with reference to breast milk cytokines/chemokines, there are findings suggesting an association between race and immune markers in amniotic fluid and cord blood $(12,13)$. Regarding cord blood, race/ethnicity appears to have the greatest influence on innate immune responses (12). Regarding amniotic fluid, higher IL-6 and CXCL8 concentrations were found in African-American women compared with Caucasian women (13). Notably, previous studies investigating breast milk cytokine/chemokine levels often ignored such covariates $(2,4,5)$. Thus, at present, it is incompletely understood whether maternal disease characteristics and/or nondisease characteristics influence the levels of immune markers in breast milk. We aim to determine whether maternal disease (asthma, rhinitis, eczema, and urogenital infection during pregnancy) and nondisease characteristics (smoking, pet exposure, race, preconception body mass index (BMI), age, and education) influence the levels of cytokines, chemokines, and IgA in breast milk.

'Department of Epidemiology and Biostatistics, University of South Carolina, Columbia, South Carolina; ${ }^{2}$ Division of Epidemiology, Biostatistics and Environmental Health, School of Public Health, University of Memphis, Memphis, Tennessee; ${ }^{3}$ Food Allergy and Immunology Laboratory, Department of Food Science and Human Nutrition, Michigan State University, East Lansing, Michigan; ${ }^{4}$ Department of Obstetrics and Gynecology, Medical University of South Carolina, Charleston, South Carolina. Correspondence: Wilfried Karmaus (karmaus1@memphis.edu) 


\section{RESULTS}

A total of 178 participants were enrolled in our study. Of these, $64.6 \%$ (115/178) breastfed and/or provided breast milk samples. There was no meaningful difference between women who provided information on history of allergies in the whole cohort and in the subset with breast milk samples $(P>0.05$; data not shown). Of the 115 women who participated, $28.1 \%$ $(n=32)$ had asthma, $52.6 \%(n=60)$ had rhinitis, and $8.8 \%(n=$ 10) had eczema (Table 1 ). Regarding race/ethnicity, $66.7 \%$ were Caucasian/white, $17.5 \%$ African American, and 15.8\% were

Table 1. Characteristics of the participants

\begin{tabular}{|c|c|}
\hline Variables & $\%(n)$ \\
\hline \multicolumn{2}{|l|}{ Race } \\
\hline Caucasian/white & $66.7(77)$ \\
\hline African American & $17.5(20)$ \\
\hline Other & $15.8(18)$ \\
\hline \multicolumn{2}{|l|}{ Maternal education } \\
\hline$\geq$ High school & $7.9(9)$ \\
\hline Technical school & $21.9(25)$ \\
\hline College graduate & $31.6(36)$ \\
\hline Graduate school & $38.6(44)$ \\
\hline \multicolumn{2}{|l|}{ Maternal smoke exposure } \\
\hline Participant smoked & $9.7(11)$ \\
\hline Secondhand smoke at home & $5.3(6)$ \\
\hline \multicolumn{2}{|l|}{ Maternal history of allergy } \\
\hline Asthma & $28.1(32)$ \\
\hline Rhinitis & $52.6(60)$ \\
\hline Eczema & $8.8(10)$ \\
\hline \multicolumn{2}{|l|}{ Urogenital infections $s^{\mathrm{a}}$} \\
\hline Yes & $43.4(49)$ \\
\hline \multicolumn{2}{|l|}{ Sex of the infant } \\
\hline Male & $48.7(55)$ \\
\hline \multicolumn{2}{|l|}{ Mode of delivery } \\
\hline Spontaneous vaginal delivery & $41.6(47)$ \\
\hline Vaginal delivery after induction & $33.6(38)$ \\
\hline Cesarean section & $24.8(28)$ \\
\hline \multicolumn{2}{|l|}{ Pet owner } \\
\hline Yes & $65.8(75)$ \\
\hline \multicolumn{2}{|l|}{ Season of child's birth } \\
\hline Spring (March-May) & $23.9(27)$ \\
\hline Summer (June-August) & $23.0(26)$ \\
\hline Fall (September-November) & $20.4(23)$ \\
\hline \multirow[t]{2}{*}{ Winter (December-February) } & $32.7(37)$ \\
\hline & Mean $(5 \%, 95 \%) ; n$ \\
\hline Maternal age during pregnancy & $30.9(21.7,38.9) ; 111$ \\
\hline Maternal body mass index $\left(\mathrm{kg} / \mathrm{m}^{2}\right)$ & $29.2(20.5,41.1) ; 111$ \\
\hline
\end{tabular}

classified as others. More than half of the women had at least 4 years of college education. At the beginning of the pregnancy and throughout gestation, $9.7 \%$ had smoked. A urogenital infection during gestation was reported by $43.4 \%$. We compared the information on urogenital infection with medical records in 28 women. The Kappa statistic was 0.60 (95\% confidence interval $=0.29-0.91)$, indicating a moderate agreement.

Immune markers IL-12 (p70), IL-4, IL-10, IL-1 $\beta$, and CCL11 (eotaxin) in whey were not considered in the statistical analyses because high proportions of nondetectable values (low or undetectable concentrations) were obtained (14). Immune markers IL-5 and IL-13 showed low concentrations in whey (geometric mean: 0.12 and $0.19 \mathrm{pg} / \mathrm{ml}$ respectively; Table 2), whereas IgA, interferon (IFN)- $\gamma$-induced protein 10 (IP-10 or CXCL10), and TGF- $\beta 1$ showed higher concentrations than other immune markers (geometric mean: $12.97 \mathrm{mg} / \mathrm{ml}, 141.25$ $\mathrm{pg} / \mathrm{ml}$, and $469.21 \mathrm{pg} / \mathrm{ml}$, respectively).

The results of general linear regression models using $\log 10$ based concentrations indicate that IL-13, TGF- $\beta 1$, IgA, CXCL8, and CXCL10 were not significantly associated with maternal history of rhinitis, asthma, or eczema (Tables 3 and 4). Because Tables 3 and 4 provide estimates of effects on a $\log 10$ base scale, we also present the geometric means for maternal history of rhinitis, asthma, eczema, and selected factors (Table 5). Women with a history of asthma were more likely to have higher concentrations of IL-5 in breast milk whey than women without the same $(P=0.02$; Table 3$)$. The concentration of IL-5 was $0.28 \mathrm{pg} / \mathrm{ml}$, whereas in unaffected mothers, it was $0.08 \mathrm{pg} / \mathrm{ml}$ (Table 5). Compared with mothers unaffected by rhinitis, the levels of IL-5 and IFN- $\gamma$ in whey were lower in mothers with a history of rhinitis (Tables 3-5). In mothers with a history of eczema, the concentration of IL-6 was $0.66 \mathrm{pg} / \mathrm{ml}$ compared with $2.22 \mathrm{pg} / \mathrm{ml}$ in unaffected mothers $(P=0.04$; Tables 4 and 5$)$.

Among the other risk factors, a urogenital infection during gestation was associated with a threefold decrease in CXCL8

Table 2. Immune marker concentrations in breast milk whey

\begin{tabular}{|c|c|c|c|c|}
\hline $\begin{array}{l}\text { Immune markers } \\
\text { (concentrations in } \\
\mathrm{pg} / \mathrm{ml} \text { for all, except } \\
\text { lgA (in mg/ml) })^{b}\end{array}$ & $N$ & $\begin{array}{c}\text { Geometric } \\
\text { mean }\end{array}$ & Median & $5 \%, 95 \%$ \\
\hline IL-5 & 84 & 0.12 & 0.10 & $0,2.12$ \\
\hline IL-6 & 84 & 1.93 & 1.06 & $0.75,20.64$ \\
\hline CXCL8 & 84 & 6.55 & 5.60 & $0.46,265.07$ \\
\hline IL-13 & 115 & 0.19 & 0.46 & $0,5.31$ \\
\hline IFN- $\gamma$ & 115 & 3.06 & 1.59 & $1.07,102.53$ \\
\hline CXCL10 & 115 & 141.25 & 270.25 & $1.91,10,184.64$ \\
\hline TGF- $\beta 1$ & 86 & 469.21 & 600.88 & $7.7,1,823.90$ \\
\hline $\lg A$ & 89 & 12.97 & 4.35 & $0.13,2,931.48$ \\
\hline \multicolumn{5}{|c|}{ 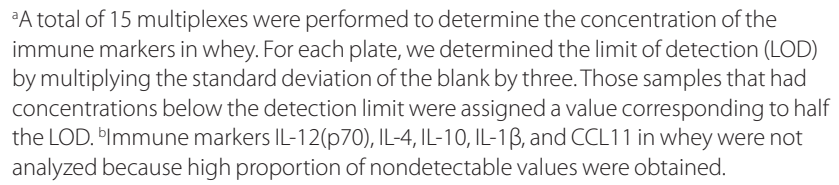 } \\
\hline
\end{tabular}


Table 3. Estimates of maternal characteristics (log 10 base) on T-helper cell 2 cyto- and chemokines, anti-inflammatory cytokines, and lgA

\begin{tabular}{|c|c|c|c|c|c|c|c|c|}
\hline \multirow[b]{3}{*}{ Variables $^{\mathrm{a}}$} & \multicolumn{4}{|c|}{ T-helper cell 2 cytokines and chemokines } & \multirow{2}{*}{\multicolumn{2}{|c|}{$\begin{array}{c}\begin{array}{c}\text { Anti-inflammatory } \\
\text { cytokines }\end{array} \\
\text { TGF- } \beta 1(n=81) \\
\end{array}$}} & \multirow{2}{*}{\multicolumn{2}{|c|}{$\begin{array}{c}\text { Secretory } \lg \mathrm{A} \\
\lg \mathrm{A}(n=85)\end{array}$}} \\
\hline & \multicolumn{2}{|c|}{$\mathrm{IL}-5(n=81)$} & \multicolumn{2}{|c|}{ IL-13 $(n=107)$} & & & & \\
\hline & Estimate (SE) & $\begin{array}{c}P \\
\text { value }\end{array}$ & $\begin{array}{c}\text { Estimate } \\
\text { (SE) }\end{array}$ & $\begin{array}{c}P \\
\text { value }\end{array}$ & Estimate (SE) & $\begin{array}{c}P \\
\text { value }\end{array}$ & Estimate (SE) & $\begin{array}{c}P \\
\text { value }\end{array}$ \\
\hline Asthma & $0.67(0.29)$ & 0.02 & $0.41(0.29)$ & 0.16 & $-0.12(0.13)$ & 0.34 & $0.02(0.43)$ & 0.95 \\
\hline Rhinitis & $-0.60(0.26)$ & 0.02 & $-0.32(0.27)$ & 0.23 & $-0.16(0.12)$ & 0.17 & $0.09(0.38)$ & 0.81 \\
\hline Eczema & $0.27(0.49)$ & 0.58 & $0.55(0.46)$ & 0.25 & $-0.15(0.22)$ & 0.50 & $-0.51(0.69)$ & 0.46 \\
\hline Urogenital infections & $-0.14(0.27)$ & 0.62 & $-0.06(0.27)$ & 0.81 & $0.03(0.12)$ & 0.82 & $-0.13(0.39)$ & 0.71 \\
\hline Participant smoked during pregnancy & $-0.12(0.58)$ & 0.83 & $0.27(0.43)$ & 0.53 & $0.09(0.21)$ & 0.66 & $-0.03(0.70)$ & 0.96 \\
\hline Secondhand smoke at home during pregnancy & $-0.11(0.56)$ & 0.85 & $0.26(0.61)$ & 0.66 & $-0.19(0.25)$ & 0.47 & $-0.47(0.83)$ & 0.57 \\
\hline Pet ownership & $-0.07(0.27)$ & 0.81 & $0.20(0.27)$ & 0.46 & $-0.25(0.12)$ & 0.06 & $0.28(0.40)$ & 0.48 \\
\hline Sex of the offspring (male) & $-0.25(0.25)$ & 0.30 & $-0.26(0.25)$ & 0.29 & $0.15(0.12)$ & 0.21 & $0.30(0.38)$ & 0.42 \\
\hline African American vs. Caucasian and other race/ethnicity & $0.19(0.33)$ & 0.57 & $0.23(0.35)$ & 0.50 & $0.09(0.18)$ & 0.62 & $0.54(0.57)$ & 0.33 \\
\hline BMI & $-0.001(0.02)$ & 0.95 & $-0.05(0.02)$ & 0.01 & $0.007(0.009)$ & 0.44 & $-0.01(0.02)$ & 0.64 \\
\hline Maternal age & $-0.01(0.03)$ & 0.57 & $-0.04(0.03)$ & 0.10 & $-0.03(0.01)$ & 0.04 & $-0.001(0.04)$ & 0.97 \\
\hline \multicolumn{9}{|l|}{ Season } \\
\hline Fall & $0.71(0.33)$ & 0.04 & $0.19(0.36)$ & 0.59 & $-0.06(0.16)$ & 0.70 & $1.07(0.51)$ & 0.04 \\
\hline Spring & $0.39(0.35)$ & 0.27 & $-0.13(0.34)$ & 0.70 & $-0.09(0.15)$ & 0.56 & $0.75(0.50)$ & 0.13 \\
\hline Summer & $0.72(0.37)$ & 0.05 & $-0.31(0.36)$ & 0.39 & $-0.22(0.17)$ & 0.19 & $0.49(0.55)$ & 0.37 \\
\hline
\end{tabular}

autually adjusted for all variables listed above in addition to mode of delivery and educational level.

Bold font denotes a $P$ value of $<0.05$.

Table 4. Estimates of maternal characteristics (log 10 base) on T-helper cell 1 response associated pro-inflammatory cytokines and chemokines

\begin{tabular}{|c|c|c|c|c|c|c|c|c|}
\hline \multirow[b]{3}{*}{ Variables $^{a}$} & \multicolumn{4}{|c|}{ Cytokines } & \multicolumn{4}{|c|}{ Chemokines } \\
\hline & \multicolumn{2}{|c|}{ IL-6 $(n=78)$} & \multicolumn{2}{|c|}{ IFN- $\gamma(n=107)$} & \multicolumn{2}{|c|}{$\operatorname{CXCL8}(n=81)$} & \multicolumn{2}{|c|}{$\operatorname{CXCL10}(n=107)$} \\
\hline & Estimate (SE) & $P$ value & Estimate (SE) & $P$ value & Estimate (SE) & $P$ value & Estimate (SE) & $P$ value \\
\hline Asthma & $-0.11(0.11)$ & 0.34 & $0.01(0.15)$ & 0.97 & $0.24(0.21)$ & 0.24 & $-0.01(0.26)$ & 0.99 \\
\hline Rhinitis & $-0.19(0.11)$ & 0.08 & $-0.30(0.15)$ & 0.03 & $-0.35(0.19)$ & 0.06 & $0.10(0.24)$ & 0.67 \\
\hline Eczema & $-0.41(0.19)$ & 0.04 & $0.31(0.24)$ & 0.19 & $-0.59(0.36)$ & 0.10 & $-0.18(0.41)$ & 0.64 \\
\hline Urogenital infections & $-0.04(0.11)$ & 0.76 & $0.04(0.14)$ & 0.76 & $-0.55(0.20)$ & 0.008 & $0.10(0.24)$ & 0.67 \\
\hline Participant smoked & $0.66(0.23)$ & 0.006 & $0.41(0.22)$ & 0.06 & $0.86(0.42)$ & 0.04 & $-0.02(0.37)$ & 0.95 \\
\hline Secondhand smoke at home & $-0.13(0.23)$ & 0.57 & $0.17(0.31)$ & 0.57 & $0.89(0.44)$ & 0.04 & $0.89(0.53)$ & 0.09 \\
\hline Pet ownership & $-0.08(0.11)$ & 0.46 & $0.23(0.14)$ & 0.11 & $0.25(0.20)$ & 0.20 & $0.04(0.24)$ & 0.86 \\
\hline Sex of the offspring (male) & $0.10(0.10)$ & 0.35 & $-0.06(0.13)$ & 0.65 & $-0.08(0.17)$ & 0.64 & $0.65(0.22)$ & 0.003 \\
\hline $\begin{array}{l}\text { African American vs. Caucasian } \\
\text { and other race/ethnicity }\end{array}$ & $0.49(0.13)$ & 0.0006 & $0.39(0.17)$ & 0.03 & $0.74(0.24)$ & 0.003 & $0.32(0.30)$ & 0.34 \\
\hline BMI & $-0.01(0.01)$ & 0.38 & $-0.02(0.01)$ & 0.02 & $-0.02(0.02)$ & 0.21 & $-0.03(0.02)$ & 0.12 \\
\hline Maternal age & $0.02(0.01)$ & 0.09 & $-0.002(0.01)$ & 0.89 & $-0.01(0.01)$ & 0.51 & $-0.01(0.02)$ & 0.64 \\
\hline \multicolumn{9}{|l|}{ Season } \\
\hline Fall & $0.25(0.14)$ & 0.07 & $0.52(0.18)$ & 0.005 & $-0.15(0.24)$ & 0.56 & $-0.01(0.30)$ & 0.98 \\
\hline Spring & $0.08(0.14)$ & 0.54 & $0.27(0.17)$ & 0.11 & $-0.30(0.25)$ & 0.23 & $-0.83(0.30)$ & 0.006 \\
\hline Summer & $-0.21(0.14)$ & 0.16 & $0.23(0.18)$ & 0.22 & $-0.34(0.26)$ & 0.19 & $-0.77(0.31)$ & 0.01 \\
\hline
\end{tabular}

Bold font denotes a $P$ value of $<0.05$.

aMutually adjusted for all variables listed above, in addition to mode of delivery and educational level.

levels in breast milk whey $(3.51 \mathrm{pg} / \mathrm{ml}$ compared with $10.02 \mathrm{pg} /$ $\mathrm{ml}$; Tables 4 and 5). Gestational smoking was related to fivefold increased levels of IL-6 (8.30 pg/ml compared with 1.88 $\mathrm{pg} / \mathrm{ml}$ ) and to 13-fold increased levels of CXCL8 (Tables 3-5) compared with that in nonsmoking mothers. Interestingly, exposure to secondhand smoke at home during pregnancy was also related to approximately sevenfold higher levels of CXCL8 in whey $(22.94 \mathrm{pg} / \mathrm{ml}$ compared with $6.05 \mathrm{pg} / \mathrm{ml}$; Tables 4 and 5) compared with the levels in unexposed mothers.

If the newborn was a boy, the concentration of CXCL10 in breast milk was significantly higher than the level in the same if the infant was a girl $(P=0.003 ; 317.03 \mathrm{pg} / \mathrm{ml}$ compared with 


\section{Articles | Burch et al.}

Table 5. Geometric means of cytokines and chemokines for selected statistically significant covariates

\begin{tabular}{|c|c|c|c|c|c|c|}
\hline & $\mathrm{IL}-5(\mathrm{pg} / \mathrm{ml})$ & $\operatorname{lgA}(\mathrm{mg} / \mathrm{ml})$ & $\mathrm{IL}-6(\mathrm{pg} / \mathrm{ml})$ & $\mathrm{IFN}-\gamma(\mathrm{pg} / \mathrm{ml})$ & CXCL8 (pg/ml) & CXCL10 (pg/ml) \\
\hline \multicolumn{7}{|l|}{ Maternal history of asthma } \\
\hline Yes & $0.28^{*}$ & & & & & \\
\hline \multicolumn{7}{|l|}{ Maternal history of rhinitis } \\
\hline Yes & 0.10 & & & 2.45 & & \\
\hline \multicolumn{7}{|l|}{ Maternal history of eczema } \\
\hline Yes & & & 0.66 & & & \\
\hline No & & & $2.22^{*}$ & & & \\
\hline \multicolumn{7}{|l|}{ Urogenital infections during pregnancy } \\
\hline Yes & & & & & 3.51 & \\
\hline No & & & 1.88 & & 5.78 & \\
\hline \multicolumn{7}{|l|}{ Smoking at home } \\
\hline Yes & & & & & $22.94^{*}$ & \\
\hline No & & & & & 6.05 & \\
\hline \multicolumn{7}{|l|}{ Sex of the offspring } \\
\hline Male & & & & & & $317.03^{*}$ \\
\hline Female & & & & & & 76.10 \\
\hline African American & & & $6.60^{*}$ & $6.56^{*}$ & $27.42^{*}$ & \\
\hline \multicolumn{7}{|l|}{ Season of birth } \\
\hline
\end{tabular}

Covariates are from Tables 3 and $\mathbf{4}$.

${ }^{*} P<0.05$.

$76.10 \mathrm{pg} / \mathrm{ml}$, Tables 4 and 5). The breast milk from AfricanAmerican mothers, compared with Caucasian and other racial/ ethnic groups, had significantly higher levels of IL-6 (6.60 vs. $1.55 \mathrm{pg} / \mathrm{ml}), \mathrm{IFN}-\gamma$ (6.56 vs. 2.58 ), and CXCL8 (27.42 vs. 4.78 $\mathrm{pg} / \mathrm{ml}$; Tables 4 and 5).

A higher preconception maternal BMI was associated with decreased levels of the Th2 cytokine IL-13 $(P=0.01$, Table 3$)$ and decreased levels of the proinflammatory cytokine IFN- $\gamma(P=$ 0.02 , Table 4). Maternal age was associated with a decreased concentration of TGF- $\beta 1$ ( $P=0.04$; Table 3$)$. For season of child's birth, variations in whey concentrations were found for IL-5, IgA, IFN- $\gamma$, and CXCL10. Exposure to pets, mode of delivery, and maternal education were not significantly associated with any whey immune markers studied.

\section{DISCUSSION}

This is the first study to examine the effect of maternal history of asthma, rhinitis, and eczema on type-1/type- 2 and
T-regulatory immune markers in human breast milk, controlling for covariates. Important findings of this study include the following: (i) Maternal asthma was linked to increased levels of IL-5; (ii) maternal rhinitis was linked to decreased levels of IL-5 and IFN- $\gamma$; (iii) maternal eczema was associated with decreased levels of IL-6; (iv) urogenital infections during gestation were related to reduced CXCL8 levels; (v) gestational smoking (active or passive) was related to increased CXCL8; and active smoking was related to increased levels of IL-6; (vi) preconception maternal BMI was linked to lower levels of IL-13 and IFN- $\gamma$; (vii) African-American mothers exhibited higher levels of IL-6, IFN- $\gamma$, and CXCL8 compared with mothers in Caucasian and other racial/ethnic groups; and (viii) season of child's birth was related to variations in whey concentrations for IL-5, IgA, IFN- $\gamma$, and CXCL10. Compared with other risk factors, the impact of maternal history of asthma, rhinitis, and eczema on immune markers in breast milk was small. 
The strength of this study is the prospective design because risk factors were collected before breastfeeding and collection of breast milk samples started thereafter. Another advantage is the independent collection and analysis of clinical data and breast milk immune markers. Therefore, the qualitative and quantitative success of breastfeeding did not affect information on risk factors. With regard to selection bias, participation in studies during pregnancy and infancy depends on volunteering and a high level of dedication to study requirements. According to the South Carolina Behavioral Risk Factor Surveillance System (SC BRFSS), the prevalence of maternal history of asthma in women between 18 and 24 years of age was $25.9 \%$ (15). In our study, $29.4 \%$ of the participating mothers in the same age range reported a history of asthma, which is comparable with that in the SC BRFSS report. About $10 \%$ of the participants in our study were active smokers, whereas $10.6 \%$ were expected based on data from SC BRFSS (15).

The collection of duplicate measurements of each immune marker is likely to have improved the accuracy of the measurements. Moreover, as levels of immune markers may vary in time (16-19), we tested whether the levels of immune mediators correlated with the interval of collection after birth. None of the immune markers were correlated with the time of milk collection, which is in agreement with a recent review on breast milk immune markers (20). Hence, there was no need to control for the dates of collection of breast milk samples in the explanatory models. Finally, regarding the sample size, this study is one of the larger investigations. Only five studies reported so far on immune markers in whey had sample sizes of $\geq 100$ (20).

The median concentrations of immune markers in maternal whey, IgA, TGF- $\beta 1$, CXCL10, and IFN- $\gamma$, were comparable with those in other studies of breast milk recently reviewed by Agarwal et al. (20). The other cytokines (IL-5, IL-6, and IL-13) and chemokine (CXCL8) levels in whey were lower, although they still fell within the range reported by other studies (20).

\section{Maternal History of Asthma, Eczema, and Rhinitis}

Our findings reveal that only one of eight immune markers (IL-5) was affected by maternal asthma, two (IL-5 and IFN- $\gamma$ ) by maternal rhinitis, and one (IL-6) by maternal eczema. Contrary to what could be expected, we found that the levels of only one (IL-5) was lower in the whey of mothers with rhinitis. Two studies by Böttcher et al. $(N=39)$ and Prokesova et al. $(N=42)$ found no differences in IL-5 concentrations in breast milk between allergic and nonallergic mothers $(5,21)$. Contrary to the expectations, we showed that two (IL-6 and IFN- $\gamma$ ) of the four quantified proinflammatory cytokines were lower among mothers with a history of eczema and rhinitis, respectively. Prokesova et al. found no sizable differences between the mother's breast milk levels of IL- 6 and IFN- $\gamma$ in the healthy and the allergic groups (5). The concentrations of the two other type-1/proinflammatory cytokines/chemokines (CXCL10 and CXCL8) were not significantly affected by maternal history of asthma, eczema, or rhinitis. Only one study by Böttcher et al. reported significantly higher levels of CXCL8 in allergic mothers, both in colostrum and mature milk (19). Regarding IgA, the levels in breast milk whey were not altered by maternal history of asthma, eczema, or rhinitis.

Our results on TGF- $\beta 1$ concentration in breast milk is in agreement with three of four other studies $(5,19,22,23)$, demonstrating no differences between allergic and nonallergic mothers $(5,19,23)$. However, Rigotti et al. showed that TGF$\beta 1$ concentration in breast milk was lower in allergic women $(n=13)$ than in the control group $(n=9)(22)$. The difference between our study and the study by Rigotti et al. on TGF- $\beta 1$ in breast milk is that we quantified this cytokine in mature milk on average $2 \mathrm{wk}$ after delivery, whereas in the above-mentioned study, it was measured when the infant was 1 mo old (22).

The discrepancies found between our study and the previous reports may be due to other studies' lack of adjustment for covariates or differences in participant selection criteria, methods used to quantify immune marker concentrations, and the assessment and definition of maternal history of allergy. We separated maternal history of allergies into three groups, whereas other studies combined the three groups into a single variable. Furthermore, we obtained breast milk samples $\sim 2 \mathrm{wk}$ after delivery, whereas other authors collected the breast milk samples at about 1-4 mo of lactation.

\section{Maternal Characteristics and Other Child's Covariates}

Surprisingly, maternal urogenital infections during pregnancy and maternal characteristics such as active and passive smoking, race/ethnicity, age, preconception BMI, and child's sex and season of birth were found to alter the levels of immune markers in breast milk. These potential covariates were rarely controlled for in other studies. Tobacco smoke is considered immunotoxic, altering the levels of cytokines (24). It is surprising that only two studies have controlled for maternal smoking while investigating breast milk cytokine levels $(25,26)$. Our data suggest that exposure to smoke elevates concentrations of proinflammatory immune markers IL-6 and CXCL8.

Regarding race/ethnicity, Vélez et al. demonstrated that cytokine levels, in particular CXCL8, in amniotic fluid differed between Caucasian and African-American women (13). Our study indicates that whey from African-American mothers had increased levels of IL-6, IFN- $\gamma$, and CXCL8 compared with those of other racial/ethnic groups (Table 5). Recently, Holmlund et al. found that breast milk of women who immigrated to Sweden contained higher levels of TGF- $\beta 1$ and CXCL8 than milk from native Swedish women (27). Country of origin seems to play a role in the concentration of CXCL8 and TGF- $\beta 1$ in breast milk, which further supports the idea that race/ethnicity may influence whey cytokine levels.

There is growing evidence that obesity is associated with elevated markers of systemic inflammation (28). We found that preconception BMI was related to decreased levels of the Th2 cytokine IL-13 and Th1 cytokine IFN- $\gamma$ in whey samples. Surprisingly, only one study investigated the relationship between maternal obesity and breast milk cytokine levels (29). Collado et al. found that TGF- $\beta 2$ and SCD14 levels in the breast milk of overweight mothers were lower than the levels 
in that of normal-weight mothers, but no difference was found for IFN- $\gamma$ (29).

Evidently, season of child's birth alters the levels of breast milk immune markers (IL-5, IgA, IFN- $\gamma$, and CXCL10). Our results suggest that if the mother gave birth to a child in the fall, the levels of IL-5, IFN- $\gamma$, and IgA were significantly increased in breast milk. If the mother gave birth in the spring or summer, CXCL10 concentrations in breast milk were six times lower than those who gave birth in the winter. Only one study by Böttcher et al. reported no differences in breast milk composition by season (21). Snijders et al. did adjust for season of breast milk collection, but did not report whether the levels of immune components varied (23). Further studies are needed to explore fluctuations of breast milk immune markers by different seasons.

Our results suggest that mothers with urogenital infections during pregnancy have lower breast milk levels of CXCL8. We are not aware of previous studies examining breast milk immune markers for this factor. However, two previous studies examined plasma cytokines in vaginal/urinary infection cases $(30,31)$. One study identified significantly increased levels of IL-5, IL-10, and IFN- $\gamma$ in patients with urogenital infections (30). Another study, reported significantly elevated plasma levels of IL- $1 \beta$ and IL-6 in patients with vaginal/urinary infection (31). Further investigations are needed to understand why and how urogenital infections may affect breast milk CXCL8 immune marker.

We expected that mothers with a history of allergic disorders would exhibit elevated markers of type- 2 immunity (IL-5 and IL-13) and reduced markers of type-1 (IFN- $\gamma$ ) and T-regulatory (TGF- $\beta 1$ ) immunity in breast milk. However, our data showed only that IL-5 was higher if the mother had a history of asthma ( 0.28 compared with $0.08 \mathrm{pg} / \mathrm{ml})$. Recently, we reported that higher whey levels of IL-5 were a risk for asthmalike symptoms in children at ages of 6 and 12 mo (14). Thus, maternal history of asthma may partially contribute to the risk of asthma by increasing IL-5 levels in breast milk (history of maternal asthma $\rightarrow$ IL-5 in whey $\rightarrow$ asthma-like symptoms). Therefore, in an additional path analysis, we tested this indirect path. As this path did not reach statistical significance (indirect path $P=0.07$ ) for maternal asthma, we do not consider the differential levels of only IL- 5 to be critical.

In summary, a maternal history of allergy should not be a concern if the mother wants to breastfeed her newborn. Nondisease characteristics, such as race/ethnicity, smoking, and season of child's birth, show stronger associations with immune markers in breast milk than maternal history of allergies. Hence, there is a need in future studies to take these characteristics into account.

\section{METHODS}

\section{Participants}

This work was derived from two prospective cohort studies that were approved by the Institutional Review Boards at the University of South Carolina, the Medical University of South Carolina, and Palmetto Health (Columbia, SC). All participants signed a written consent form either in English or in Spanish. Expecting mothers in the second trimester were enrolled between April 2008 and January 2010 in Columbia and Charleston, SC, in prenatal clinics and prenatal classes. Eligibility criteria included (i) aged 18 y or older, (ii) no chronic illness (diabetes, thyroid or adrenal disorders, or chronic infections), (iii) planned to stay in the area for at least 9 mo, and (iv) willingness to provide a breast milk sample $2 \mathrm{wk}$ after delivery.

\section{Clinical Data Collection}

The clinical data collection has been described elsewhere (14). In brief, women took part in two telephone or in-person interviews: A core demographic and baseline interview conducted before delivery and one interview 2 wk after delivery.

At the baseline interview, information was obtained about women's sociodemographic characteristics, race (African American, Caucasian/white, or other), maternal age, preconception weight and height, cigarette use before and since the beginning of pregnancy, whether cigarettes were smoked inside the home, education level (less than high school, some college, college graduate, or graduate school), pet exposure, and maternal history of allergies (asthma, rhinitis, and eczema).

Information on maternal history of allergies was based on questions used in the International Study of Asthma and Allergies in Childhood questionnaire (32). Maternal history of asthma, wheezing and whistling in the chest, and eczema was obtained by asking: "Have you ever had asthma?" and "Have you ever had wheezing or whistling in the chest at any time in the past?" The next two questions were grouped to define rhinitis: "Have you ever had hay fever?" and "Have you ever suffered-in the absence of a cold-from an itchy stuffy or runny nose and/or swollen, itchy eyes?" The question "Have you ever had an itchy rash, which was coming and going for at least 6 months?" was used as an indicator of eczema.

The second interview was conducted $2-4 \mathrm{wk}$ after delivery. We gathered information on mode of delivery (spontaneous vaginal delivery, vaginal delivery after induction, and Cesarean section), sex of the offspring, relationship of the delivery date to seasons, and history of vaginal/urinary infection during pregnancy (14). The information on vaginal infection was validated with obstetric records in 28 participants.

\section{Breast Milk Collection and Preparation}

Women were asked to provide a breast milk sample about $2 \mathrm{wk}$ after delivery. Breast milk collection and preparation are described elsewhere (14). Briefly, the participant provided at least $15 \mathrm{ml}$ of breast milk, using an electric breast pump provided by the study, on average $3 \mathrm{wk}$ after delivery (range: 1-8 wk). All women followed a detailed breast milk collection protocol. Women were asked to collect breast milk in the morning and after putting the baby to the breast. The nipple and surrounding breast area were cleaned with sterile wipes before breast milk collection. All breast milk samples were collected in sterile plastic bottles (Medela, McHenry, IL; $80 \mathrm{ml}$ ). Research staff picked up the breast milk sample from the participant's residence. Within $1 \mathrm{~h}$ of collection, all samples $(15 \mathrm{ml}$ each) were transferred to sterile centrifuges tubes and spun at $2,900 \mathrm{rpm}$ for $10 \mathrm{~min}$ at $4{ }^{\circ} \mathrm{C}$. Fat was removed; centrifugation and fat removal steps were repeated until all fat was taken out. Finally, the cell pellet was removed. The isolated whey was aliquoted and stored in a $-80^{\circ} \mathrm{C}$ freezer until preparation for immunoassays.

\section{Immunoassay Protocols}

The concentrations of IL- $1 \beta$, IL-4, IL-5, IL-6, CXCL8 (IL-8), IL-10, IL-12(p70), IL-13, IP-10 or CXCL10, CCL11, and IFN- $\gamma$ in whey were assayed using the Bioplex Protein Array system (Bio-Rad Laboratories, Hercules, CA). This multiplex system allows for the assessment of several immune markers in the same Biorad custommade Bio-Plex Pro human cytokine, chemokine, and growth factor multiplex plate. Enzyme-linked immunosorbent assays were used to determine concentrations of IgA (Immunology Consultants Laboratory, Portland, OR) and TGF- $\beta 1$ (R\&D Systems, Minneapolis, MN). To activate latent TGF- $\beta 1$ to immunoreactive TGF- $\beta 1$ detectable by the Quantikine TGF- $\beta 1$ immunoassay, we followed the manufacturer's procedure. All assays were conducted according to the 
manufacturer's kit instructions. Each sample, including standards and the blank, was assayed in duplicate. A total of 15 multiplexes were performed to determine the concentration of the immune markers in whey. For each plate, we determined the limit of detection by multiplying the standard deviation of the blank by three. Those samples that had concentrations below the detection limit were assigned a value corresponding to half the limit of detection.

We focused on levels of type-1/pro-inflammatory cytokines/chemokines (IFN- $\gamma$, CXCL10, IL-1 $\beta$, IL-6, IL-12(p70), and CXCL8), type-2/pro-allergic cytokines/chemokines (IL-4, IL-5, IL-13, and CCL11), T-regulatory/anti-inflammatory cytokines (TGF- $\beta 1$ and IL-10), and the secretory IgA.

\section{Statistical Analysis}

A log transformation (base 10) was used for all immune markers because they were not normally distributed. General linear regression models were used to estimate the effect of independent variables on log-transformed levels of immune markers.

The risk factors considered in the analysis were maternal race, maternal smoking during pregnancy, exposure to secondhand smoke at home, pet ownership, urogenital infections during pregnancy, mode of delivery, preconception BMI (weight/height ${ }^{2}\left(\mathrm{~kg} / \mathrm{m}^{2}\right)$ ), sex of the offspring, and season of child's birth. Information on smoking was separated into active (participant smoked) and passive (secondhand smoke at home) smoke exposure. Maternal education was considered a confounder. All risk factors were simultaneously entered into the general linear regression models. To describe the effect of selected independent factors, geometric means were calculated. All statistical analyses were performed using Statistical Analysis System (SAS) version 9.2 (SAS Institute, Cary, NC).

\section{ACKNOWLEDGMENTS}

We gratefully acknowledge the cooperation of the women who participated in this study. We thank the Breastfeeding and Child Health (BACH) and Pregnancy, Environment and Child Health (PEACH) study teams. We acknowledge Denise Altman for her insightful comments and help with the recruitment of participants.

\section{STATEMENT OF FINANCIAL SUPPORT}

The study was funded by the Thrasher Research Foundation (Salt Lake City, UT; award 02826-6). Initial participant enrollment was supported by a grant from the US Environmental Protection Agency (R830825-01-0).

Disclosure: The authors declare no conflict of interest.

\section{REFERENCES}

1. Greer FR, Sicherer SH, Burks AW; American Academy of Pediatrics Committee on Nutrition; American Academy of Pediatrics Section on Allergy and Immunology. Effects of early nutritional interventions on the development of atopic disease in infants and children: the role of maternal dietary restriction, breastfeeding, timing of introduction of complementary foods, and hydrolyzed formulas. Pediatrics 2008;121:183-91.

2. Rudloff S, Niehues T, Rutsch M, Kunz C, Schroten H. Inflammation markers and cytokines in breast milk of atopic and nonatopic women. Allergy 1999;54:206-11.

3. Böttcher MF, Fredriksson J, Hellquist A, Jenmalm MC. Effects of breast milk from allergic and non-allergic mothers on mitogen- and allergen-induced cytokine production. Pediatr Allergy Immunol 2003;14: $27-34$.

4. Laiho K, Lampi AM, Hamalainen M, et al. Breast milk fatty acids, eicosanoids, and cytokines in mothers with and without allergic disease. Pediatr Res 2003;53:642-7.

5. Prokesová L, Lodinová-Zádníková R, Zizka J, et al. Cytokine levels in healthy and allergic mothers and their children during the first year of life. Pediatr Allergy Immunol 2006;17:175-83.

6. Järvinen KM, Laine ST, Järvenpää AL, Suomalainen HK. Does low IgA in human milk predispose the infant to development of cow's milk allergy? Pediatr Res 2000;48:457-62.

7. Järvinen KM, Laine S, Suomalainen H. Defective tumour necrosis factoralpha production in mother's milk is related to cow's milk allergy in suckling infants. Clin Exp Allergy 2000;30:637-43.
8. Friedman NJ, Zeiger RS. The role of breast-feeding in the development of allergies and asthma. J Allergy Clin Immunol 2005;115:1238-48.

9. Petersen KL, Marsland AL, Flory J, Votruba-Drzal E, Muldoon MF, Manuck SB. Community socioeconomic status is associated with circulating interleukin-6 and C-reactive protein. Psychosom Med 2008;70:646-52.

10. Lim RH, Kobzik L. Maternal transmission of asthma risk. Am J Reprod Immunol 2009;61:1-10.

11. Prescott SL. Effects of early cigarette smoke exposure on early immune development and respiratory disease. Paediatr Respir Rev 2008;9:3-9; quiz 10.

12. Gold DR, Bloomberg GR, Cruikshank WW, et al. Parental characteristics, somatic fetal growth, and season of birth influence innate and adaptive cord blood cytokine responses. J Allergy Clin Immunol 2009;124:1078-87.

13. Velez DR, Fortunato SJ, Morgan N, et al. Patterns of cytokine profiles differ with pregnancy outcome and ethnicity. Hum Reprod 2008;23:1902-9.

14. Soto-Ramírez N, Karmaus W, Yousefi M, Zhang H, Liu J, Gangur V. Maternal immune markers in serum during gestation and in breast milk and the risk of asthma-like symptoms at ages 6 and 12 months: a longitudinal study. Allergy Asthma Clin Immunol 2012;8:11.

15. Soto-Ramírez N, Smith M, Helms K, Wilkerson K. Breastfeeding initiation among WIC participants in South Carolina, 2004-2008. South Carolina Department of Health and Environmental Control, 2011. (http://www. dhec.sc.gov/co/phsis/biostatistics/prams/SP_DEL_WIC_BF_initiation_ FINAL.pdf).

16. Garofalo R, Chheda S, Mei F, et al. Interleukin-10 in human milk. Pediatr Res 1995;37(4 Pt 1):444-9.

17. Yilmaz HL, Saygili-Yilmaz ES, Gunesacar R. Interleukin-10 and -12 in human milk at 3 stages of lactation: a longitudinal study. Adv Ther 2007;24:603-10.

18. Bryan DL, Hawkes JS, Gibson RA. Interleukin-12 in human milk. Pediatr Res 1999;45:858-9.

19. Böttcher MF, Jenmalm MC, Björkstén B, Garofalo RP. Chemoattractant factors in breast milk from allergic and nonallergic mothers. Pediatr Res 2000;47:592-7.

20. Agarwal S, Karmaus W, Davis S, Gangur V. Immune markers in breast milk and fetal and maternal body fluids: a systematic review of perinatal concentrations. J Hum Lact 2011;27:171-86.

21. Böttcher MF, Jenmalm MC, Garofalo RP, Björkstén B. Cytokines in breast milk from allergic and nonallergic mothers. Pediatr Res 2000;47:157-62.

22. Rigotti E, Piacentini GL, Ress M, Pigozzi R, Boner AL, Peroni DG. Transforming growth factor-beta and interleukin-10 in breast milk and development of atopic diseases in infants. Clin Exp Allergy 2006;36:614-8.

23. Snijders BE, Damoiseaux JG, Penders J, et al. Cytokines and soluble CD14 in breast milk in relation with atopic manifestations in mother and infant (KOALA Study). Clin Exp Allergy 2006;36:1609-15.

24. Macaubas C, de Klerk NH, Holt BJ, et al. Association between antenatal cytokine production and the development of atopy and asthma at age 6 years. Lancet 2003;362:1192-7.

25. Ermis B, Yildirim A, Tastekin A, Ors R. Influence of smoking on human milk tumor necrosis factor-alpha, interleukin-1beta, and soluble vascular cell adhesion molecule-1 levels at postpartum seventh day. Pediatr Int 2009;51:821-4.

26. Zanardo V, Nicolussi S, Cavallin S, et al. Effect of maternal smoking on breast milk interleukin-1alpha, beta-endorphin, and leptin concentrations and leptin concentrations. Environ Health Perspect 2005;113:1410-3.

27. Holmlund U, Amoudruz P, Johansson MA, et al. Maternal country of origin, breast milk characteristics and potential influences on immunity in offspring. Clin Exp Immunol 2010;162:500-9.

28. Sharabiani MT, Vermeulen R, Scoccianti C, et al. Immunologic profile of excessive body weight. Biomarkers 2011;16:243-51.

29. Collado MC, Laitinen K, Salminen S, Isolauri E. Maternal weight and excessive weight gain during pregnancy modify the immunomodulatory potential of breast milk. Pediatr Res 2012;72:77-85.

30. Chen KS, Wang PH, Yang SF, et al. Significant elevation of a Th2 cytokine, interleukin-10, in pelvic inflammatory disease. Clin Chem Lab Med 2008;46:1609-16.

31. Lee SA, Tsai HT, Ou HC, et al. Plasma interleukin-1beta, $-6,-8$ and tumor necrosis factor-alpha as highly informative markers of pelvic inflammatory disease. Clin Chem Lab Med 2008;46:997-1003.

32. Asher MI, Keil U, Anderson HR, et al. International Study of Asthma and Allergies in Childhood (ISAAC): rationale and methods. Eur Respir J 1995;8:483-91. 